\title{
A PERCEPÇÃO DOS MICRO-EMPRESÁRIOS DA CIDADE DE SÃO PAULO QUANTO AO SISTEMA TRIBUTÁRIO BRASILEIRO
}

\author{
PERCEPTION OF SMALL ENTERPRISES OF SÃO PAULO \\ CITY OF THE BRAZILIAN TAX SYSTEM
}

\author{
Recebido: 11/02/2016 - Aprovado: 28/04/2016 - Publicado: 30/06/2016 \\ Processo de Avaliação: Double Blind Review
}

\author{
Marcus Vinicius Moreira Zittei1 \\ Doutor em Ciências Contábeis \\ Fundação Universidade Regional de Blumenau \\ marcuszittei@zittei.com.br
}

\section{Leonardo Fabris Lugoboni}

Doutorando em Administração pela FEA-USP - Faculdade de Economia, Administração e Contabilidade

Faculdade de Economia, Administração e Contabilidade - USP

Insper Instituto de Ensino e Pesquisa

Centro Universitário FECAP

Centro Estadual de Educação Tecnológica Paula Souza

leo_fabris@hotmail.com

\section{Renata Cavalcante de Souza}

Especialista em Gestão Tributária

Centro Estadual de Educação Tecnológica Paula Souza

renatacsouza19@yahoo.com.br

\footnotetext{
${ }^{1}$ Autor para correspondência: FURB:. Rua Antônio da Veiga, 140- Victor Konder-Campus 1 sala R- Blumenau - SC- CEP: 89012-900
} 
RESUMO: Tributo é elemento inerente à existência do Estado, necessário a organização da sociedade e ponto crucial da relação Estado-cidadão. No Brasil o segmento das micro e pequenas empresas tem fundamental importância no ambiente econômico, pois de acordo com pesquisas do SEBRAE representa $98 \%$ do número de empresas abertas no País. Diante dessa realidade o presente artigo tem como objetivo identificar qual é a percepção dos micro e pequenos empresários na cidade de São Paulo em relação aos tributos cobrados no Brasil. O estudo apresenta uma pesquisa de campo junto a diversos empreendedores situados na cidade de São Paulo para identificar sua percepção em relação à carga tributária brasileira. O resultado dessa pesquisa demonstra que apesar da maioria dos micro e pequenos empresários terem um grau de instrução alto, têm pouco conhecimento com relação ao tema.

Palavras-chave: Tributos; Micro e Pequena Empresa; Carga Tributária.

ABSTRACT: Taxes are inherent elements in the existence of the State, being necessary - to the organization of the society and fundamental in the state-citizen relationship. In Brazil, the small and medium enterprises segment has fundamental importance in the economic scenery. According to research made by SEBRAE, this segment represents $98 \%$ of the number of listed companies in the country. Given this reality, the present article aims to identify which is the perception of micro and small businessman in the city of São Paulo in relation to the taxes levied in Brazil. The study presents the concepts of taxes and micro and small enterprises awarded by the doctrine and legislation, the legality of taxation specific to - those small businesses. And finally, it presents a field research in several micro entrepreneurs located in the city of São Paulo in order to identify their perception of the Brazilian tax burden. The article reports only the perception of the population studied, - making no reference to political leanings or parties. The result of this research shows that although the majority of micro and small - businessman have a high level of education, where the most of them are graduates and some of them post-graduates, they have little knowledge on the issue,. In most cases they get confused by simple questions on the subject and most of the times they are embarassed for not giving the right importance to a fundamental aspect for the development and growth of their enterprises. 
Keywords: Tax; Samll and Medium Enterprises; Tax Rate.

\section{INTRODUÇÃO}

Segundo o SEBRAE em parceria com o DIEESE (2000-2011), no Brasil existem cerca de 6 milhões de empresas e desse total, 98\% são micro e pequenas empresas (MPE's).

Diante desses números, as microempresas e as empresas de pequeno porte são as maiores fontes de recursos e captadoras de mão-de-obra do país em todos os setores: comércio, indústria e prestação de serviços. Com essa importância na economia brasileira, torna-se evidente a necessidade dessas empresas se regulamentarem não apenas as obrigações, mas principalmente os direitos e garantias especiais, tanto no aspecto jurídico-econômico quanto no aspecto tributário.

Para que haja essa regulamentação é necessário que os empresários e/ou gestores que conduzam essas empresas, tenham um conhecimento técnico e amplo não apenas do negócio em si, mas também dos aspectos anteriormente comentados, e nesse estudo, especificamente, no aspecto tributário.

Contudo, fica evidente a necessidade da economia brasileira de proporcionar a esses pequenos empreendedores a importância de conhecer todos os aspectos fundamentais para a sobrevivência de suas empresas, estimulando-os a trabalhar- de forma estratégica, de acordo com o que a lei brasileira proporciona às micro e pequenas empresas, e tendo como resultado uma diminuição de mortalidade das mesmas e obviamente um aumento do desenvolvimento, progresso, crescimento dos pequenos negócios.

Diante do exposto a questão identificada para esta pesquisa é: Qual é a percepção dos microempresários na cidade de São Paulo quanto ao sistema tributário brasileiro? O objetivo geral deste trabalho é identificar qual é a percepção dos micro e pequenos empresários da cidade de São Paulo em relação aos tributos cobrados pelo governo as suas micro e pequenas empresas, espera-se ainda, verificar se esses micro empreendedores têm conhecimento sobre a carga tributária brasileira para conseguir gerir os seus negócios.

\section{REFERENCIAL TEÓRICO}

\subsection{SISTEMA TRIBUTÁRIO NACIONAL}

Um país para atingir seus objetivos fundamentais necessita de recursos, para dentre tantas obrigações, proporcionar principalmente, o bem estar da coletividade. 
Diante dessa realidade, a Constituição Federal de 1988, trata do Sistema Tributário Nacional desde os princípios gerais até a competência da União, Estados, Distrito Federal e municípios para cobrança dos tributos, que tem como função principal suprir a necessidade do país de gerar tais recursos (PALMA; 2006).

Sendo assim, o Sistema Tributário Brasileiro é um conjunto de elementos que atuam harmoniosamente visando o alcance de um determinado fim, que neste caso tem como função consagrar os princípios e normas gerais do direito tributário, instituir limitações ao poder de tributar, estabelecer a repartição das receitas tributárias e administrar e fiscalizar todo e qualquer tributo arrecadado.

\begin{abstract}
Designa-se por sistema tributário o conjunto, mais ou menos coerente, de instituições, regras e práticas tributárias, consideradas seja nas suas recíprocas relações, seja quanto aos efeitos globalmente produzidos sobre a vida econômica e social. O sistema envolve sempre organicidade. Não basta a mera enumeração dos tributos para se ter um sistema. Compreende outros elementos que não a simples nomenclatura dos tributos. Engloba princípios e definições básicas, que denotem harmonia e coerência dos componentes SILVA (1975, p.2 e 3).
\end{abstract}

\title{
$1.2 \quad$ TRIBUTOS
}

Segundo o conceito estampado no artigo $3^{\circ}$ do Código Tributário Nacional - CTN (2005, p. 665): "tributo é toda prestação pecuniária compulsória, em moeda ou cujo valor nela se possa exprimir, que não constitua sanção de ato ilícito, instituída em lei e cobrada mediante atividade administrativa plenamente vinculada".

Neste sentido, entende-se que se trata de uma obrigação legal que o contribuinte tem seja ele pessoa física ou jurídica, e não deve ser confundida com uma penalidade. Tem como principais características de um tributo que: Ele é sempre devido a um ente público; visa a arrecadação de recursos financeiros para o Estado realizar suas tarefas; sua arrecadação fundamenta-se no poder de império do Estado; é obrigatório; deve ser pago em moeda nacional ou em valor que nela se exprima; cobrado mediante atividade administrativa plenamente vinculada e deve ser previsto em lei (SHINGAKI, 2007).

Nunes (1995, p. 20) entende que:

Se o tributo deve nascer na lei, esta deve conter todos os elementos da norma jurídica tributária, hipótese de incidência do tributo, seus sujeitos ativo e passivo, base de cálculo e alíquotas. Além disso, só a lei pode regular quando e como deve ser feito o pagamento dos tributos, quais os órgãos que farão os lançamentos, a cobrança e a fiscalização, assim como estabelecer descrição das infrações e as respectivas sanções.

Dispõe, ainda, o CTN (2005, p. 665): 
Art. $4^{\circ}$ A natureza jurídica específica do tributo é determinada pelo fato gerador da respectiva obrigação, sendo irrelevantes para qualificá-la:

I - a denominação e demais características formais adotadas pela lei;

II - a destinação legal do produto da sua arrecadação.

Apesar de o tributo ser uma fonte de recursos para o Estado, ele só poderá cobrá-lo quando houver o fato gerador, além de necessitar de um ato administrativo que o declare existente. Esse ato de administração pública representa a primeira manifestação da atividade de que fala a lei na definição do tributo, e é o chamado lançamento.

Para Fabretti (2003), a natureza jurídica específica do tributo, se é imposto, taxa ou contribuição é determinada por seu fato gerador. Esta é a concretização de determinada hipótese prevista na lei que faz gerar a obrigação de pagar o tributo. Por exemplo: hipótese de incidência: prestar serviços. Prestado o serviço de fato, concretizada a hipótese de incidência, segue o mandamento: pagar Imposto sobre Serviços (ISS). Logo, o art. $5^{\circ}$ do CTN (2005, p. $665)$ dispõe: "os tributos são impostos, taxas e contribuições de melhoria".

\subsection{ESPÉCIES DE TRIBUTOS}

Os tributos classificam-se cientificamente em duas espécies: tributos não vinculados e tributos vinculados. No entanto, o art.149 da CF, cujas normas tributárias passaram a vigorar a partir de $1^{\circ}$ de março de 1989, introduziu como nova espécie tributária as contribuições especiais (FABRETTI, 2006).

\subsubsection{Impostos}

Tributos não vinculados são os que, uma vez instituídos em lei, são devidos, independentemente de qualquer atividade estatal em relação ao contribuinte. Portanto, não estão vinculados a nenhuma prestação específica do Estado ao sujeito passivo (NUNES, 1995). Trata-se da espécie denominada imposto, definida no art. 16 do CTN (2005, p. 668) como: "Imposto é o tributo cuja obrigação tem por fato gerador uma situação independentemente de qualquer atividade estatal específica, relativa ao contribuinte".

Ou seja, o imposto é a mais comum das espécies de tributos e são de competência Federal, Estadual (Estados e Distrito Federal) e Municipal. Como exemplos, pode-se citar o Imposto de Renda (IR), o Imposto sobre Circulação de Mercadorias (ICMS) e o Imposto sobre a Prestação de Serviços (ISS). 


\subsubsection{Taxas}

São tributos extrafiscais, através dos quais o Estado busca recuperar os gastos com a prestação de serviços públicos divisíveis. A diferença essencial entre impostos e taxas é que, para que sejam cobradas as taxas, exige-se que o poder tributário exerça uma atividade específica ao contribuinte, enquanto que para cobrar impostos, o Estado não necessita exercer, qualquer atividade específica em relação ao contribuinte (PALMA, 2006).

Para Federighi (2000, p. 50):

As taxas cobradas pela União, pelos Estados, pelo Distrito Federal e pelos Municípios, no âmbito de suas respectivas atribuições, têm como fato gerador o exercício regular do Poder de Polícia, ou a utilização, efetiva ou potencial, de serviço público específico e divisível, prestado ao contribuinte ou posto à sua disposição.

As taxas podem ser criadas pela União, pelos Estados, pelo Distrito Federal e pelos Municípios. Como exemplo, a taxa de coleta de lixo e a taxa para o corpo de bombeiros.

\subsubsection{Contribuições de Melhoria}

É também um tributo vinculado e instituído para fazer face ao custo de obras públicas decorrentes da valorização imobiliária. Para que se configure o fato gerador em concreto da contribuição de melhoria, não basta que haja obra, é preciso observar a relação direta entre a obra e a valorização (ABREU, 2008).

A contribuição de melhoria cobrada pela União, pelos Estados, pelo Distrito Federal, ou pelos Municípios, no âmbito de suas respectivas atribuições, é instituída para fazer face ao custo de obras públicas de que decorra valorização imobiliária, tendo como limite total a despesa realizada, e como limite individual o acréscimo de valor que da obra resultar para cada imóvel beneficiado. FEDERIGHI (2000, p. 52).

Segundo Palma (2006), a contribuição de melhoria é raramente utilizada pela administração pública brasileira, resumindo-se praticamente à cobrança dos gastos com pavimentação de via pública, receita que muitos autores preferem classificar como taxa e não como contribuição de melhoria que realmente é.

O CTN dispõe que os tributos são impostos, taxas e contribuições de melhoria. A $\mathrm{CF}$, por sua vez, prevê, além desses tributos, os empréstimos compulsórios e as contribuições sociais ou especiais". IUDÍCIBUS e POHLMANN (2006).

Para Ichihara (2009, p.88): 
Os empréstimos compulsórios são verdadeiros tributos e, em nosso entender, não constituem uma espécie tributária autônoma. [...]. Com base na interpretação sistemática, os "empréstimos compulsórios" e as "contribuições sociais ou parafiscais" classificam-se como sendo não vinculados e vinculados (direta ou indiretamente); dependendo da materialidade de seu fato gerador, poderão ser enquadrados ora como imposto, ora como taxa, ora como contribuição de melhoria.

\subsection{CONTRIBUINTE}

O sujeito passivo da obrigação principal é a pessoa obrigada ao pagamento de tributo, é o cidadão ou a pessoa jurídica a quem a lei atribui à obrigação de recolher o tributo.

O art. 121 do CTN (2005, p. 685) conceitua o sujeito passivo firmando que:

\footnotetext{
Art. 121. Sujeito passivo da obrigação principal é a pessoa obrigada ao pagamento de tributo ou penalidade pecuniária.

Parágrafo único. O sujeito passivo da obrigação principal diz:

I - contribuinte, quando tenha relação pessoal e direta com a situação que constitua o respectivo fato gerador;

II - responsável, quando, sem revestir a condição de contribuinte, sua obrigação decorra de disposição expressa de lei.
}

Este trabalho tratará em específico do sujeito passivo da obrigação, ou seja, pessoa jurídica (PJ) de pequeno porte, definidos como Micro Empreendedor Individual (MEI), Micro Empresas (ME) ou Empresas de Pequeno Porte (EPP).

\subsection{O MICROEMPREENDEDOR INDIVIDUAL (MEI), A MICROEMPRESA (ME) E A EMPRESA DE PEQUENO PORTE (EPP)}

A Constituição Federal Brasileira de 1988 definiu uma política de tratamento favorecido para as Microempresas (ME) e para as Empresas de Pequeno Porte (EPP), como exemplo desse favorecimento, definiu-se que a União, os Estados e os Municípios devem dispensar às ME e EPP, devidamente definidas em lei, tratamento jurídico diferenciado, visando incentivá-las pela simplificação de suas obrigações administrativas, tributárias, previdenciárias e creditícias, ou pela eliminação ou redução dessas obrigações por meio da lei (OLIVEIRA, 2002).

Para Duarte e Silva, (2001, p. 15 e 16):

Por que houve essa referência às empresas de pequeno porte? Porque o legislador constitucional entendeu que elas são uma realidade cada vez mais presente no País, através da geração de empregos, captação de rendimentos e circulação de bens e serviços. Por isso, são consideradas responsáveis por uma parcela significativa do desenvolvimento econômico brasileiro. Mas por suas características próprias de estrutura reduzida e atividade simplificada, não poderiam receber o mesmo 
tratamento tributário que aquele dispensado às grandes empresas, que apresentam, essencialmente, uma estrutura e atividade mais complexas, sem que tal diferenciação constitua privilégio ou discriminação, práticas vedadas pela própria constituição.

Considera-se Microempreendedor Individual (MEI) o empresário individual a que se refere o art. 966 da Lei n ${ }^{\circ}$ 10.406, de 10 de janeiro de 2002 - Código Civil, que tenha auferido receita bruta, no ano-calendário anterior, de até $\mathrm{R} \$ 60.000 .00$ (sessenta mil reais), que seja optante pelo Simples Nacional e que exerça atividade permitida ao MEI.

O Estatuto Nacional da Microempresa e da Empresa de Pequeno Porte (2008, p. 22) define as MPE, no art. $3^{\circ}$ incisos I e II:

Para os efeitos desta Lei Complementar, consideram-se microempresas ou empresas de pequeno porte a sociedade empresária, a sociedade simples e o empresário a que se refere o art. 966 da Lei 10.406, de 10/01/2002, devidamente registrados no Registro de Empresas Mercantis ou no Registro Civil de Pessoas Jurídicas, conforme o caso, desde que:

I - no caso das microempresas, o empresário, a pessoa jurídica, ou a ela equiparada, aufira, em cada ano-calendário, receita bruta igual ou inferior a RS240.000,00 (duzentos e quarenta mil reais).

II - no caso das empresas de pequeno porte, o empresário, a pessoa jurídica, ou a ela equiparada, aufira em cada ano-calendário, receita bruta superior a $\mathrm{R} \$ 240.000,00$ (duzentos e quarenta mil reais) e igual ou inferior a $\mathrm{R} \$ 2.400 .000,00$ (dois milhões e quatrocentos mil reais)

Com a formalização o empreendedor adquire benefícios de diversas formas, seja para ele e sua família, quando poderão contar com os benefícios da Previdência Social: auxíliodoença, aposentadoria, salário-maternidade, pensão e auxílio-reclusão; seja na facilidade em obter crédito junto aos bancos, conseguindo abrir conta bancária e pedir empréstimos, entre outros (CARTILHA DO MICROEMPREENDEDOR INDIVIDUAL, 2010).

As empresas de pequeno porte formam um segmento importante no mercado. Devido a estarem próximas as empresas de médio porte, trazem reais possibilidades de crescimento dos negócios, além de gerarem muitos empregos. Se as comparar com as microempresas, pode dizer que elas têm um faturamento muito maior e baixa taxa de mortalidade.

Porém, os mesmos benefícios proporcionados às microempresas são assegurados às empresas de pequeno porte, no que diz respeito ao tratamento jurídico diferenciado e simplificado nos campos administrativo, tributário, previdenciário, trabalhista, creditício e de desenvolvimento empresarial.

As vantagens de ser microempresa estão relacionadas com as facilidades que os governos (federal, estadual e municipal) proporcionam a essas empresas, principalmente no tratamento tributário. Isso favorece a competitividade e viabiliza o negócio. Além do benefício fiscal, o pequeno empresário conta com créditos que são colocados a sua disposição, por intermédio de bancos oficiais, e com menos 
burocracia na prática dos atos formais, necessários a sua existência legal. OLIVEIRA (2002, p. 12).

\subsection{TRIBUTAÇÃO DAS MPE'S}

Para o Microempreendedor Individual a formalização tem um custo relativamente baixo em termos tributários. Conforme a Cartilha do Microempreendedor Individual (2010) a inscrição como empreendedor individual é gratuita, não há pagamento de imposto para o governo federal, caso exerça atividade de comércio, recolherá o ICMS mensal de apenas R\$ 1,00 , se exercer atividade de serviços, pagará o ISS mensal de apenas $\mathrm{R} \$ 5,00$ e por fim, para a previdência deverá pagar $\mathrm{R} \$ 33,90$ por mês (representa $5 \%$ do salário mínimo que é reajustado no início de cada ano). Além de não precisar ter uma contabilidade formal, deverá apenas preencher um formulário simples com o total de suas compras, vendas e seu lucro e mantê-lo guardado em seu poder, para ter um controle do negócio viabilizando seu próprio crescimento e desenvolvimento.

Conforme o Estatuto das MPE (2008, p. 24):

Art. 12 Fica instituído o Regime Especial Unificado de Arrecadação de Tributos e Contribuições devidos pelas Microempresas e Empresas de Pequeno Porte - Simples Nacional.

Art. 13 O Simples Nacional implica o recolhimento mensal, mediante documento único de arrecadação, dos seguintes impostos e contribuições:

I - Imposto sobre a Renda de Pessoa Jurídica - IRPJ

II - Imposto sobre Produtos Industrializados - IPI

III - Contribuição Social sobre o Lucro Líquido - CSLL

IV - Contribuição para o Financiamento da Seguridade Social - COFINS

V - Contribuição para o PIS/Pasep

VI - Contribuição para a Seguridade Social

VII - Imposto sobre Operações Relativas à Circulação de Mercadorias e Sobre Prestações de Serviços de Transporte Interestadual e Intermunicipal e de Comunicação - ICMS

VIII - Imposto sobre Serviços de Qualquer Natureza.

A Lei $\mathrm{n}^{\circ}$ 9.317/96 dispõe sobre o regime tributário das ME e das EPP e institui o Sistema Integrado de Pagamento de Impostos e Contribuições por elas devidos - Simples. "Note-se que não se trata de "imposto único", como às vezes escrevem e dizem os menos avisados, mas da unificação do pagamento de diversos impostos e contribuições num único documento de arrecadação federal, denominado Darf - Simples”. FABRETTI (2003, p. 117). 
A Lei $n^{\circ}$ 9.317/96 é lei federal e, portanto, só pode dispor dos tributos federais, entretanto em convênio com alguns Estados e/ou Municípios o ICMS e o ISS passaram também a serem recolhidos no mesmo documento denominado Darf, facilitando muito a vida das MPE.

Para Oliveira (2002, p. 26) "Nos estados e municípios em que não há convênio nesse sentido o ISS (imposto municipal) e o ICMS (imposto estadual) devem ser recolhidos em guias separadas do Darf - Simples, de acordo com o que estabelecer a legislação de cada Município e de cada Estado.”

Considera-se importante mencionar ainda, as contribuições e os impostos não unificados no Simples Federal, ou seja, o recolhimento dos impostos unificados, não exclui a incidência dos seguintes impostos ou contribuições, devidos na qualidade de contribuinte ou responsável, em relação aos quais será observada a legislação aplicável às demais pessoa jurídicas:

\subsubsection{Contribuições:}

a) Contribuição previdenciária sobre folha de pagamento de empregados;

b) Pagamento a transportador rodoviário autônomo (descontar e recolher a contribuição previdenciária que incide sobre a remuneração);

c) FGTS do empregado, com base no percentual estabelecido e aplicável sobre o valor da remuneração;

d) Contribuição individual dos sócios feita para a previdência;

e) Contribuição sindical, devida anualmente pela empresa e proporcional ao capital social;

f) $\quad \mathrm{CPMF}-$ Contribuição Provisória sobre Movimentação Financeira.

\subsubsection{Impostos:}

a) IOF - Imposto sobre operações de crédito, câmbio e seguro ou relativo a títulos e valores mobiliários;

b) II - Imposto sobre importação de produtos estrangeiros;

c) IE - Imposto sobre exportação, para o exterior, de produtos nacionais ou nacionalizados; 
d) ITR - Imposto sobre a propriedade territorial rural, quando devido pela empresa;

e) IR - Imposto de renda incidente sobre o ganho obtido na alienação de ativo permanente;

f) IRF - Imposto de renda retido na fonte, incidente sobre aplicações financeiras ou renda variável, que deve ser considerado como tributado exclusivamente na fonte. O valor do imposto retido na fonte decorrente dessas aplicações não é recuperável. Também deve ser descontado dos empregados ou de terceiros, com base na aplicação da tabela progressiva, o imposto de renda na fonte sobre rendimentos pagos às pessoas físicas (assalariados e autônomos), e com base em alíquotas fixas e variáveis sobre os rendimentos pagos às pessoas jurídicas. Há limite mínimo para a retenção. Com base na legislação atual, se o valor do imposto for inferior a esse limite mínimo, não precisa ser feita a retenção e, consequentemente, o recolhimento.

\section{METODOLOGIA}

A presente pesquisa aplicada é do tipo exploratória-descritiva, pois além de descrever uma situação ou área de interesse, de modo factual e preciso; segundo Silva (2003, p. 65):

A pesquisa exploratória é realizada em área na qual há pouco conhecimento acumulado e sistematizado. Tem como objetivo proporcionar maior familiaridade com o problema, para torná-lo mais explícito ou para construir hipóteses. O pesquisador pode planejar uma pesquisa exploratória para encontrar elementos necessários que lhe permitam, em contato com determinada população, obter os resultados que deseja ou servir para levantar possíveis problemas de pesquisa.

De acordo com Lakatos e Marconi (2010) quanto ao propósito, foi realizada uma pesquisa de avaliação formativa, seguido o procedimento de investigação quantitativa, que consiste em investigação com finalidade de analisar as características dos fatos e tem como finalidade fornecer dados para a verificação de hipóteses. Além disso, tem como objetivo a coleta sistemática sobre populações.

Para tanto se utilizou o método dedutivo, além da técnica de coleta dos dados primários “pesquisa de campo" (REA e PARKER, 2000). 
Os sujeitos envolvidos na pesquisa são microempresários da Cidade de São Paulo, com seus estabelecimentos situados em diversos bairros da capital paulistana. O instrumento de coleta de dados será um questionário semi-estruturado que buscará elementos característicos dos sujeitos pesquisados quanto à percepção do sistema tributário brasileiro com relação à cobrança de tributos às suas micro e pequenas empresas.

O universo da pesquisa está representado por aproximadamente 88 microempresários e como limitação do estudo, apresentam-se o especo geográfico (um município e diversos bairros deste município) e as variações regionais (formação cultural de um povo), que impedem a generalização dos dados para outras cidades, mas permite replicação do mesmo modelo de análise.

\section{RESULTADO E ANÁLISE DA PESQUISA}

\subsection{CARACTERIZAÇÃO DA AMOSTRA E PERFIL DOS RESPONDENTES}

Devido a dificuldade de obter informações dos micro e pequenos empresários em seus estabelecimentos de trabalho, seja pela falta de tempo, pela falta de vontade ou até mesmo por medo, desconfiança; é importante ressaltar que a maioria das opiniões aqui refletidas foram emitidas por micro e pequenos empresários encontrados em salas de aula da faculdade e em cursos oferecidos pelo SEBRAE específicos para microempreendedores. Contudo, isso mostra que a maioria dos respondentes tem nível superior, especificamente $40 \%$, além dos pós-graduados, cerca de $20 \%$; totalizando $60 \%$ dos respondentes.

A partir do agrupamento dos dados coletados, constata-se que homens e mulheres estão relativamente empatados no quesito ser dono do próprio negócio, nota-se ainda que a maioria dos respondentes são adultos com mais de 30 anos, não havendo se quer um respondente com idade entre 18 e 21 anos. Outra constatação interessante é a de que $50 \%$ dos microempreendedores têm suas empresas com tempo de vida menor que três anos, o que aumenta a preocupação com a hipótese de fechamento dessas empresas, pois conforme uma pesquisa feita pelo IBGE em 2012 e divulgada no site do SEBRAE (2012) 48\% das empresas brasileiras fecham as portas depois de três anos. Diante dessa situação fica evidente a necessidade que a economia brasileira tem em proporcionar a esses pequenos empreendedores formas, meios de conhecer todos os aspectos fundamentais para a sobrevivência dos seus negócios, incluindo a tão complexa carga tributária brasileira. 
TABELA 1 - Percepção dos respondentes com relação aos tributos no Brasil.

\begin{tabular}{|c|c|c|c|c|c|c|c|c|c|c|c|c|}
\hline \multirow[b]{3}{*}{ Assertivas } & \multicolumn{12}{|c|}{ Resultado de análise de dados } \\
\hline & \multicolumn{2}{|c|}{1} & \multicolumn{2}{|c|}{2} & \multicolumn{2}{|c|}{3} & \multicolumn{2}{|c|}{4} & \multicolumn{2}{|c|}{5} & \multicolumn{2}{|c|}{ TOTAL } \\
\hline & $\begin{array}{c}\text { Obs } \\
.\end{array}$ & $\%$ & $\begin{array}{c}\text { Obs } \\
.\end{array}$ & $\%$ & $\begin{array}{c}\text { Obs } \\
. \\
\end{array}$ & $\%$ & $\begin{array}{c}\text { Obs } \\
.\end{array}$ & $\%$ & $\begin{array}{c}\text { Obs } \\
.\end{array}$ & $\%$ & $\begin{array}{c}\text { Obs } \\
.\end{array}$ & $\%$ \\
\hline $\begin{array}{l}1 \text { - Empresa de } \\
\text { Pequeno Porte e } \\
\text { Micro empresa } \\
\text { são a mesma } \\
\text { coisa, só } \\
\text { diferencia o } \\
\text { nome. }\end{array}$ & 28 & $32 \%$ & 37 & $42 \%$ & 3 & $3 \%$ & 15 & $17 \%$ & 5 & $6 \%$ & 88 & $100 \%$ \\
\hline $\begin{array}{l}2 \text { - Os tributos } \\
\text { são compostos } \\
\text { apenas pelos } \\
\text { impostos, taxas e } \\
\text { contribuições de } \\
\text { melhoria. }\end{array}$ & 17 & $19 \%$ & 21 & $24 \%$ & 13 & $15 \%$ & 29 & $33 \%$ & 8 & $9 \%$ & 88 & $100 \%$ \\
\hline $\begin{array}{l}3 \text { - Os } \\
\text { empréstimos } \\
\text { compulsórios e as } \\
\text { contribuições } \\
\text { sociais também } \\
\text { são tipos de } \\
\text { tributos. }\end{array}$ & 11 & $13 \%$ & 19 & $22 \%$ & 18 & $21 \%$ & 31 & $36 \%$ & 7 & $8 \%$ & 86 & $100 \%$ \\
\hline $\begin{array}{l}\text { - A Micro } \\
\text { empresa é } \\
\text { obrigada a ser } \\
\text { tributada pelo } \\
\text { Simples } \\
\text { Nacional. } \\
\end{array}$ & 16 & $18 \%$ & 17 & $20 \%$ & 11 & $13 \%$ & 33 & $38 \%$ & 10 & $11 \%$ & 87 & $100 \%$ \\
\hline $\begin{array}{l}5 \text { - O que o } \\
\text { contador fala que } \\
\text { tem que pagar, eu } \\
\text { pago. }\end{array}$ & 22 & $25 \%$ & 36 & $41 \%$ & 2 & $2 \%$ & 22 & $25 \%$ & 6 & $7 \%$ & 88 & $100 \%$ \\
\hline $\begin{array}{l}6 \text { - FGTS e INSS } \\
\text { são } \\
\text { impostos/encargo } \\
\text { s específicos } \\
\text { apenas para } \\
\text { empregados. }\end{array}$ & 31 & $36 \%$ & 28 & $32 \%$ & 4 & $5 \%$ & 18 & $21 \%$ & 6 & $7 \%$ & 87 & $100 \%$ \\
\hline $\begin{array}{l}7 \text { - O Simples } \\
\text { Nacional engloba } \\
\text { os tributos } \\
\text { federais, } \\
\text { estaduais e }\end{array}$ & 2 & $2 \%$ & 11 & $13 \%$ & 27 & $31 \%$ & 35 & $40 \%$ & 12 & $14 \%$ & 87 & $100 \%$ \\
\hline
\end{tabular}

REMIPE- Revista de Micro e Pequenas Empresas e Empreendedorismo da Fatec Osasco 


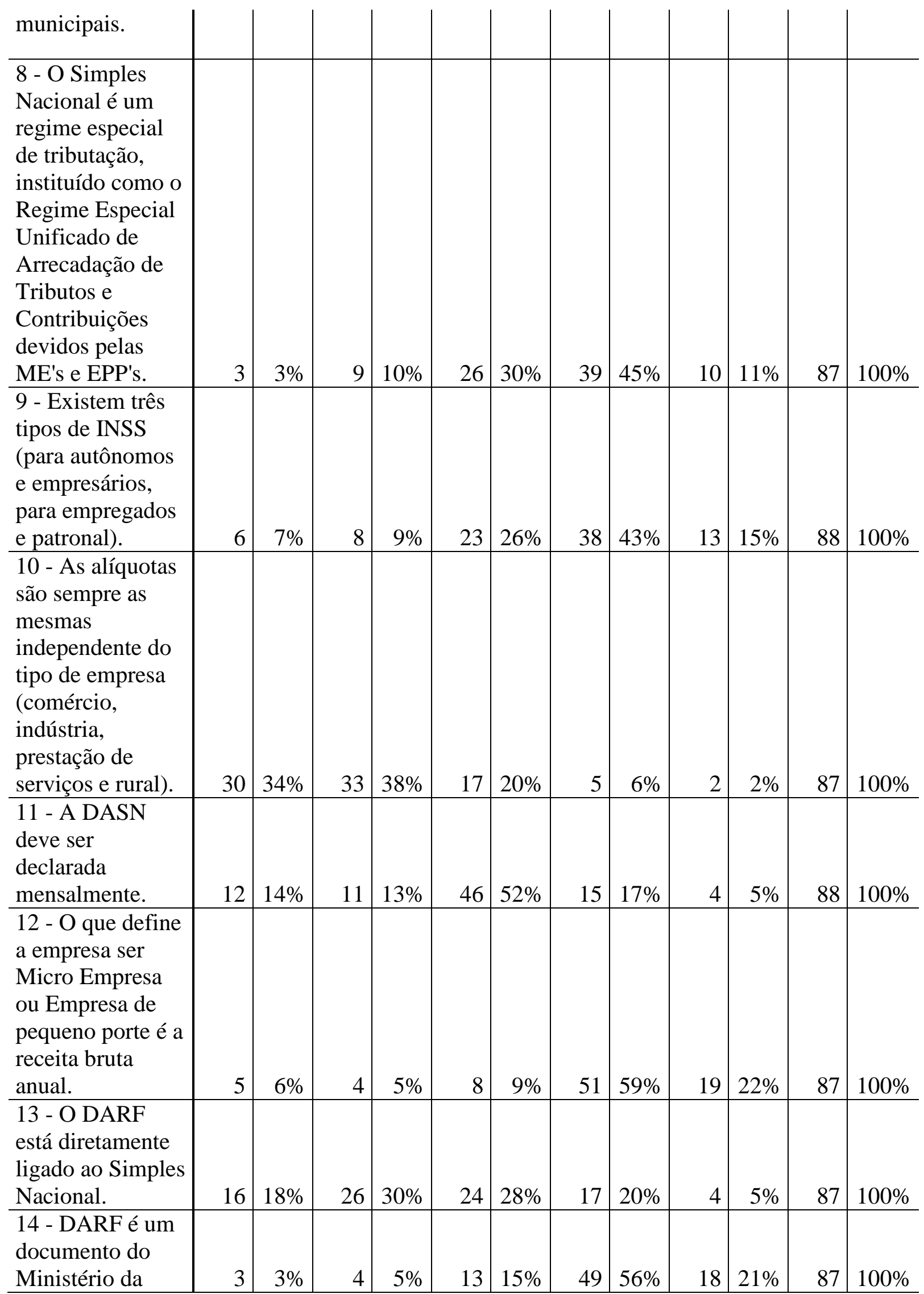


Fazenda e da

Secretaria da

Receita Federal.

15 - O Estado

tributa as

operações do

comércio através

do ICMS.

16 - O SENAI, o

SESI e o SESC

fazem partes das

taxas quando se

fala em tributos.

17 - Atualmente

existem no Brasil

cerca de 105

tributos.

18 - Ao pagar o

DARF, o

empresário está

pagando o IRPJ,

o IPI, a CSLL, o

PIS/PASEP, a

COFINS, a

contribuição para

o INSS (pessoa

jurídica), o ICMS

e o ISS.

19 - O Município

tributa as

operações de

prestação de

serviços através

do ISS.

Média Total

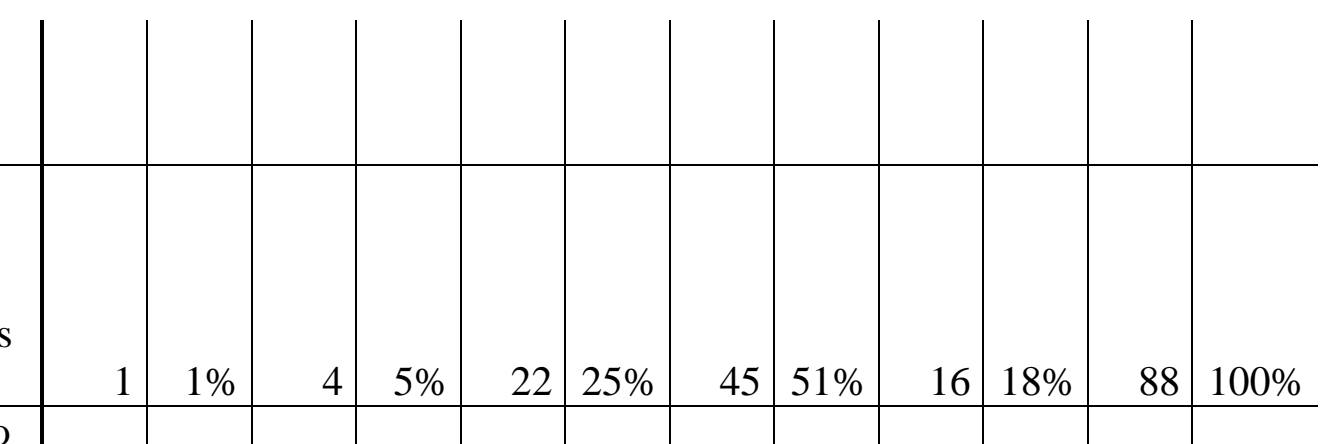

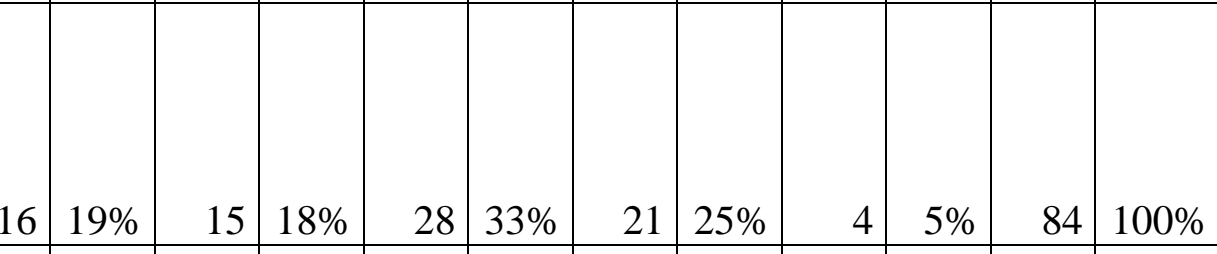

\begin{tabular}{l|l|l|l|l|l|l|l|l|l|l|l} 
& & & & & & & & & & & \\
3 & $3 \%$ & 7 & $8 \%$ & 67 & $77 \%$ & 7 & $8 \%$ & 3 & $3 \%$ & 87 & $100 \%$ \\
\hline
\end{tabular}

Fonte: dados da pesquisa

\subsection{APLICAÇÃO DO QUESTIONÁRIO E ANÁLISE DOS DADOS}

Com a pesquisa concluída e a análise realizada, entre as primeiras constatações está a aparente falta de comprometimento dos microempresários a respeito dos tipos de tributos e do montante que pagam. Apesar da maioria dos respondentes, especificamente $66 \%$ afirmarem que não pagam tudo que o contador diz que tem que pagar, afirmarem que primeiro eles 
analisam o tributo para depois decidirem se tem que pagar ou não; a realidade é que a grande maioria tem visão difusa de quanto os tributos representam do seu faturamento, inclusive $32 \%$ afirmaram que eles confiam e fazem tudo o que o contador "manda", ou seja, apesar da maioria dos respondentes terem um nível de instrução alto, o assunto abordado fez com que muitos ficassem confusos e envergonhados por não saberem coisas tão básicas e fundamentais para o andamento do seu negócio.

No quesito tributos no geral aproximadamente $40 \%$ dos respondentes sabem que os tributos são compostos por impostos, taxas, contribuições de melhoria, empréstimos compulsórios e contribuições sociais, enquanto 36\% não souberam responder, um índice consideravelmente alto. Tratando-se de FGTS e INSS, 68\% entendem que o FGTS é somente para empregados, porém o INSS além de ser para empregados pode ser recolhido pelos próprios microempreendedores, por autônomos e também patronal foi o que disse $58 \%$ dos respondentes. Continuando a análise nota-se que os microempreendedores entendem que quem tributa as operações de ICMS é o Estado e quem tributa as operações de ISS é o município, levando em consideração que pouco mais de $70 \%$ dos respondentes afirmaram isso. Com relação ao SENAI, SESI e SESC, os respondentes ficaram confusos, 37\% discordaram que se trata de taxas quando se fala em tributos, $30 \%$ concordaram e $33 \%$ não souberam responder, ou seja, a pequena maioria acertou quando discordou, pois esses três tributos são as famosas Contribuições para o "Sistema S" e não taxas.

Com relação ao entendimento sobre o Simples Nacional, $49 \%$ concordaram que a micro empresa é obrigada a ser tributada pelo Simples Nacional, enquanto 38\% discordaram e $13 \%$ não souberam responder. É fato que existem algumas formas de tributação, de apuração do lucro; entre elas está o Lucro Presumido, o Lucro Real, o Lucro Arbitrado e o Simples Nacional, sendo este último à maioria das opções das micro e pequenas empresas unicamente como o próprio nome diz por se tratar de ser uma forma mais simplificada, mais fácil de entender e consequentemente se manter em dia com a legislação tributária, mas não por obrigatoriedade. Ou seja, neste quesito considerar que metade dos respondentes estão entendidos sobre a forma de tributação de seu negócio, enquanto a outra metade se quer sabe que sua empresa poderia ser tributado de uma outra forma.

Por outro lado, mais da metade dos respondentes, ou seja, 54\% sabe que o Simples Nacional engloba os tributos Federais, Estaduais e Municipais e 56\% sabe que o mesmo é um 
regime especial de tributação, instituído como o Regime Especial Unificado de Arrecadação de Tributos e Contribuições devidos pelas ME's e EPP's.

Outro ponto relacionado ao Simples Nacional é a questão do antigo DARF, atual DAS, $28 \%$ não souberam responder, enquanto a maioria exatamente $48 \%$ dos respondentes discordou que o DAS está diretamente ligado ao Simples Nacional, o que é verdade, considerando que DAS é a sigla de Documento de Arrecadação Simplificada, um documento do Ministério da Fazenda e da Secretaria da Receita Federal Brasileira, ou seja, é o boleto utilizado para pagamento de tributos administrado pela Receita Federal do Brasil. Ressaltando que existem dois modelos de DAS em vigor, o DAS Comum, utilizado para pagamentos de receitas federais pelas pessoas físicas e jurídicas (Lucro Real, Lucro Arbitrado e Lucro Presumido exceto as optantes pelo Simples Nacional); e o DAS Simples, utilizado exclusivamente por pessoas jurídicas enquadradas como Microempresa e Empresa de Pequeno Porte, independente de serem tributas pelo Simples Nacional.

Ainda com relação ao DAS, a maioria dos respondentes acertou, exatamente 77\%, quando concordaram que ele é um documento do Ministério da Fazenda e da Secretaria da Receita Federal; por outro lado, os micro empresários ficaram divididos quando se afirmou sobre, os tributos que estão inclusos ao pagar o DAS (IRPJ, IPI, CSLL, PIS/PASEP, COFINS, contribuição para o INSS (pessoa jurídica), ICMS e ISS; 27\% discordou, 22\% não souberam responder e $29 \%$ concordou. Esse resultado reafirma que os micro empresários não só estão confusos, como estão muito desinformados a respeito da tributação de seus negócios, fazendo com que a preocupação aumente sobre o risco de fechamento das microempresas após 3 anos de abertura. Se quer, eles fazem ideia de quantos tributos tem atualmente no Brasil, a maioria, 77\%, optaram pela opção "não sei” para este quesito, muitos alegaram que acham que são muito mais do que 105 , no entanto, sabe-se que apesar de não serem poucos, os atuais tributos são em torno de 85 .

Apesar da complexidade do tema para a maioria dos respondentes, existem algumas informações que são muito bem entendidas pelos microempresários questionados, como por exemplo; Empresa de Pequeno Porte e Microempresa definitivamente não são a mesma coisa, e para nossa surpresa $74 \%$ das respostas foram de acordo com isso, além desse percentual excelentíssimo, a maioria dos respondentes mencionaram no momento dessa questão que existiam além das Micro e Pequenas Empresas, as Médias e as Grandes Instituições. Outro ponto muito bem esclarecido entre os respondentes é que para as empresas se enquadrarem 
em Micro, Pequenas, Médias e/ou Grandes Empresas, vai depender especificamente da receita bruta anual, foi o que afirmou $80 \%$ dos respondentes, ou seja, o porte da empresa é definido de acordo com o faturamento anual de cada uma delas; portanto, conforme sua receita for aumentando, ela é obrigada por lei a ir mudando, aumentando de porte também.

O entendimento "superficial" sobre as alíquotas também está positivo entre os respondentes, pois $72 \%$ discordaram quando se afirmou que as alíquotas são sempre as mesmas independentes do tipo de empresa (comércio, indústria, prestação de serviços e rural). E como se sabe as alíquotas são distintas, dependem não só do tipo da empresa, mas também do porte e do tipo de serviço e/ou produto prestado/comercializado.

Por fim, é importante ressaltar o item que mais chamou a atenção no questionário, à questão da DASN. A maioria dos respondentes foi bem clara quando afirmaram que nunca tinham visto essa sigla na vida e consequentemente nem imaginavam o que ela significava, como consequência $52 \%$ de respondentes que optaram por responder "não sei"; enquanto $26 \%$ discordaram e $22 \%$ concordaram, ambos optaram responder por dedução, por achismo e a pequena maioria $26 \%$, acabou acertando, pois a DASN atualmente extinta, era uma declaração anual e não mensal.

\section{CONSIDERAÇÕES FINAIS}

Numa situação ideal, os cidadãos brasileiros (trabalhadores, consumidores, autônomos; micro, pequenos, médios e grandes empresários) deveriam conhecer a estrutura do Estado, o seu modelo de gestão e a política tributária, bem como acompanhar a arrecadação dos tributos e o destino que os administradores públicos dão aos recursos arrecadados. No entanto, é sabido que a realidade é bem diferente, a maioria das pessoas não sabe que são contribuintes e estão recolhendo diariamente tributos para o governo, e que este tem como função principal gerar qualidade social, ou seja, tem o dever de utilizar os recursos arrecadados para custear serviços básicos para a população como, saúde, saneamento, educação, transporte, segurança pública, assistência social, habitação, urbanismo entre tantos outros. Diante deste cenário e levando em consideração que $98 \%$ das empresas brasileiras são micro e pequenas empresas, surgiu a vontade de se fazer esta pesquisa, na qual tem como problema: Qual é a Percepção dos microempresários quanto ao Sistema Tributário Brasileiro? E que tem como objetivo identificar a percepção dos micro e pequenos empresários quanto 
aos tributos cobrados pelo governo às suas pequenas empresas, e também constatar se eles têm o mínimo de conhecimento possível sobre a carga tributária brasileira para conseguir gerir os seus negócios com esperteza tributária suficiente para ter progresso nos negócios.

O Sistema Tributário Brasileiro é complexo, confuso e regressivo, ou seja, é injusto, é o tipo de sistema que quem ganha menos acaba pagando mais, se comparar em proporção; pois os tributos estão por toda parte, embutidos em todo e qualquer produto e/ou serviço que adquirir, mas existe àqueles cidadãos mal informados que acham que só quem paga imposto é quem ganha mais, quem faz declaração de IRPF, por exemplo, e que eles não tem direito nenhum de cobrar o que é dever do Estado. Tratando-se de Pessoa Jurídica no âmbito tributário, neste caso as micro e pequenas empresas, é fato que existem alguns benefícios, como por exemplo, à apuração e recolhimento dos impostos e contribuições, denominados Regime Unificado de Arrecadação de Tributos e Contribuições devidos por essas empresas Simples Nacional; também conhecido por SUPER SIMPLES. A principal característica desse regime é a possibilidade de recolhimento, mediante regime único de arrecadação, de impostos e contribuições de competência federal, estadual e municipal. Dentro desse contexto, o Tributo é uma obrigação do cidadão para com o Estado, obrigatória - imponível a todos - que deve ser paga em dinheiro, que deve ser estabelecida em lei e decorrente de atos lícitos (ou seja, excluem-se atos criminosos, os quais são passíveis de outras penalidades - multa, prisão, etc.), cuja cobrança deva decorrer exclusivamente de ações estatais voltadas à sociedade. Os tributos são subdivididos em espécies e sua arrecadação é vinculada a uma destinação especifica, ou seja, a uma atividade administrativa vinculada como diz o conceito de tributo e são elas: IMPOSTOS - Financiamento Geral das Atividades do Estado; TAXAS Contraprestação por serviços públicos, específico e divisível para cada contribuinte (efetivo ou potencial) e/ou decorrentes do poder de polícia; CONTRIBUIÇÕES - financiamento específico para financiar política pública especifica e determinada (Melhoria; Sociais, Previdenciários, Intervenção Domínio Econômico). Além disso, pode dividir os Tributos quanto à categoria econômica sobre o qual estes recaem - os chamados fatos geradores tributários. São elas: RENDA - ou seja, tudo aquilo que se aufere pela realização do trabalho; PATRIMÔNIO - propriedade de bens (móveis e imóveis); ATIVIDADE ECONÔMICA circulação de riquezas. O Sistema Tributário Nacional, tal como existe atualmente, foi criado buscando harmonizar as relações da sociedade de forma a se atender aos seus princípios fundamentais, como também de forma a se respeitar o pacto federativo sob o qual vive-se. 
Entretanto, vale ressaltar a extrema importância de entendê-lo para que os contribuintes possam diante da lei se planejar, evitando assim o pagamento indevido e/ou duplo de tributos, garantindo uma maior receita nos seus negócios.

Os resultados da pesquisa demonstram que a percepção dos micro e pequenos empresários é preocupante, pois apesar da maioria serem instruídos, cerca de $60 \%$ graduados e alguns pós-graduados, o conhecimento sobre o sistema tributário brasileiro, especificamente da carga tributária para micro e pequenas empresas, é mínimo, muitos inclusive responderam a algumas questões pelo que achavam só para não ficar com a pesquisa totalmente respondida na opção "não sei”. Ficou evidente a surpresa dos respondentes ao constatar que os mesmos desconhecem o básico quando se fala em tributos e reconhecem que estão muito acomodados deixando tudo nas mãos dos contadores e consequentemente não dando a devida importância para esse aspecto relevante e fundamental para o andamento do negócio. A pesquisa demonstrou ainda que o assunto abordado despertou uma curiosidade e uma vontade dos respondentes em irem buscar informações sobre o assunto, irem estudar e tentar entender melhor esse universo complexo que são os tributos e é um sistema necessário que irá existir pelo menos enquanto houver vida.

Estas são as percepções dos micro e pequenos empresários respondentes e infelizmente reflete uma posição negativa, contudo, diante do resultado da pesquisa, diante da dificuldade em encontrar artigos, trabalhos, monografias e etc. referente a este assunto e por ser um tema extremamente complexo, relevante e importante para a sociedade em geral, fica evidente a importância de mais estudos e pesquisas realizadas nesta área, para contribuir não somente com os estudantes interessados no assunto, mas também para alertar aos contribuintes em geral e principalmente aos micro e pequenos empresários sobre a importância em entender a complexa carga tributária brasileira para que os pequenos negócios sejam geridos da melhor forma possível, contribuindo assim para uma economia positiva que beneficia toda sociedade. 


\section{REFERÊNCIAS}

ABREU, Andréia. Gestão Fiscal nas Empresas: Principais Conceitos Tributários e sua Aplicação. São Paulo: Atlas, 2008.

BRASIL. Código Comercial, Código Tributário, Constituição Federal / organização Anne Joyce Angher. - 5. Ed. - São Paulo: Rideel, 2005. - (Coleção de leis Rideel. Série míni 3 em 1).

CÂMARA DOS DEPUTADOS. Cartilha do Microempreendedor Individual: Comissão de Desenvolvimento Econômico, Industrial e Comércio: 2010. Disponível em: http://bd.camara.gov.br/bd/bitstream/handle/bdcamara/3326/cartilha_microempreendedor.pdf ?sequence=1. Acesso em 07 de julho de 2012.

DUARTE, Ana Maria Benedito; SILVA, Denise Maria Perissini. Manual das Microempresas e das Empresas de Pequeno Porte. São Paulo: LTr, 2001.

FABReTTI, Láudio Camargo. Prática Tributária da Micro e Pequena Empresa. $4^{\mathrm{a}}$ ed. São Paulo: Atlas, 2000.

FABReTti, Láudio Camargo. Prática Tributária da Micro, Pequena e Média Empresa: Legislações Tributária e Empresarial, Lei do Simples, Tributação da Média Empresa. $5^{\text {a }}$ ed. São Paulo: Atlas, 2003.

FABRETTI, Láudio Camargo; FABRETTI, Dilene Ramos. Direito Tributário: para os cursos de administração e ciências contábeis. $5^{\text {a }}$ ed. São Paulo: Atlas, 2006.

FEDERIGHI, Wanderley José. Direito Tributário: Parte Geral. Série Fundamentos Jurídicos. $1^{\text {a }}$ ed. São Paulo: Atlas, 2000.

FONTOURA, Iara P.; SABATOVSKI, Emílio. Simples Nacional: estatuto nacional da Microempresa. $2^{\mathrm{a}}$ ed. Curitiba: Juruá, 2008.

G1.COM. Micro e pequenas empresas são $99 \%$ do total no país, mostra pesquisa, 2012. Disponível em http://g1.globo.com/economia/pme/noticia/2012/02/micro-e-pequenasempresas-sao-99-do-total-no-pais-mostra-pesquisa.html acesso em 12 de Mai 2012.

ICHIHARA, Yoshiaki. Direito Tributário: atualizado de acordo com as Emendas Constitucionais. 16 ed. São Paulo: Atlas, 2009.

IUDÍCIBUS, Sergio de; POHLMANN, Marcelo Coletto. Tributação e Política Tributária: uma abordagem interdisciplinar. São Paulo: Atlas, 2006.

MARCONI, Marina de Andrade; LAKATOS, Eva Maria. Fundamentos de Metodologia Científica. $7^{\mathrm{a}}$ ed. São Paulo: Atlas, 2010.

NUNES, Vidal Serrano. Direito Tributário Comentado. $2^{a}$ ed. rev., ampl., e atual. São Paulo: Angelotti, 1995. 
OLIVEIRA, Edson. Manual de Impostos e Contribuições: Para Microempresa (ME) e Empresa de Pequeno Porte (EPP). $3^{a}$ ed. São Paulo: Atlas, 2002.

PALMA, Antonio Jacinto Caleiro. Manual de Direito Empresarial. São Paulo: Quartier Latin, 2006.

REA, Louis M.; PARKER, Richard A.. Metodologia de Pesquisa: do Planejamento à execução. São Paulo: Pioneira, 2000.

SEBRAE. $48 \%$ das empresas brasileiras fecham as portas depois de três anos, 2012. Disponível em http://portal2.pr.sebrae.com.br/PortalInternet/Noticia/ci.48\%25-das-empresasbrasileiras-fecham-as-portas-depois-de-tr\%C3\%AAs-anos.print. Acesso em 04 de maio de 2013.

SHINGAKI, Mário. Gestão de Impostos: Para Pessoas Físicas e Jurídicas. $5^{\text {a }}$ ed. rev. atual. e ampl. São Paulo: Saint Paul Editora, 2007.

SILVA, Antônio Carlos Ribeiro da. Metodologia de Pesquisa Aplicada à Contabilidade: orientações de estudos, projetos, artigos, relatórios, monografias, dissertações, teses. São Paulo: Atlas, 2003.

SILVA, José Afonso da. Sistema Tributário Nacional. Co-edição. São Paulo: Editora Resenha Tributária, 1975. 